\title{
Establishment of Curriculum System of IOT Engineering Major for University of Application Technology
}

\author{
B.F. SUN \\ Computer Engineering College, Anhui Sanlian University, Hefei, China \\ Y.Q. XIA \\ Automation School, Beijing Institute of Technology, Beijing, China
}

\begin{abstract}
The present situation and development trend of IOT were introduced briefly, the talent demand status of IOT industry was described, the professional ability of the IOT industry practitioners was analyzed, and the development direction of IOT engineering major for university of application technology was pointed out. Based on these analyses, the ability developing scheme of IOT engineering major was designed to bring up the professional ability of the students who will pursue the work of IOT, and the curriculum system of IOT engineering major for university of application technology was established.
\end{abstract}

KEYWORD: Curriculum System; IOT Engineering Major; University of Application Technology

\section{INTRODUCTION TO IOT INDUSTRY}

IOT is integration and comprehensive application of a new generation of information technology, which has strong permeability, large leading role, and good benefits. The application and development of IOT is conducive to promote production, lifestyle and social management to be intelligent, meticulous and networked. IOT has significance to improve the informatization level of national economy and social life, to improve social management level and public service quality, to enhance related discipline development and technical innovation, to promote the industrial structure adjustment and development mode transformation. China has made the IOT as an important component of strategic emerging industry. According to the statistics and forecast data of Chinese IOT Research and Development Center, the scale of IOT industry in Chinese market is increasing year by year, which will reach trillion Yuan in 2016. IOT has the huge market investment prospect with the compound annual growth rate of more than $30 \%$.

From a global perspective, the current IOT industry is still in the initial stage of development, technology development and industrial application of IOT has broad prospect, this is a rare opportunity for us to keep up with the developed countries in IT field. After years of development of IOT, China have already established a certain foundation in theory research, standards development, industry cultivation and technology application, but there are many problems such as key technology, weak industrial base, potential danger of the network information security, excessive construction in some areas, etc.

\section{PROFESSIONALABILITY OF IOT}

\subsection{The talent demand status of IOT industry}

With the technology development of IOT, the communication of people to people, people to object, object to object will become desirable, but the high level professional talents of IOT is particularly scarce at present. According to the forecast of Chinese Computer and Microelectronics Industry Development Research Center, 500 thousand talents of IOT will be demanded in China in next three years. In order to realize the rapid development of Chinese IOT, we must cultivate the senior technical personnel researching, designing and manufacturing network products, at same time, we must cultivate a large number of senior engineering talents who pursue the development and application work of IOT. However, the current domestic cultivation ability is not adequate to meet the social need.

To push forward the IOT industry development coordinately, we should introduce diversification competition mechanism; harmoniously develop manufacturing industry, communication industry and application service industry which are closely related to IOT; form the IOT industry chain with coordinate and sustainable development pattern. The key task is to breakthrough the bottleneck of sensor manufacturing industry, to promote the development 
of network communication industry, and to breed application service industry. Specifically, the IOT industry has the following development directions.

1. To focus on manufacturing industry closely related to IOT apperceive function, to promote the high level development of sensor, node, gateway, RFID, two-dimensional bar code and other core manufacturing industries, to enhance the capacity of the instrument, embedded computer system and other supporting industries, to promote the growth and development of micro device, integrated circuit, micro energy and new material industry.

2. To support the manufacturing industry and operating industry which are closely related to IOT communication, to promote the development of chip and terminal manufacturing industry involving in wireless NFC, to promote the manufacturing capability of M2M terminal, communication module and network gateway products, to promote the development of M2M operating service industry, to enhance the fusion of high bandwidth, large capacity, ultra high speed cable/wireless communications network equipment manufacturing industry with IOT application.

3. To focus on breeding the IOT service industry, to encourage the innovation of operation mode, to expand the market demand of professional service, value-added service and other service, to focus on massive data storage, processing, decision making and other infrastructure service, to promote the comprehensive service industry including operating system, database, middleware, application software, embedded system, system integration and software development, etc. push the development of IOT market.

The development directions of IOT industry indicates the talent demand status of IOT industry, that is, a large number of professionals will be needed in IOT apperceive manufacturing industry, IOT communication industry and IOT service industry.

\subsection{Professional technology of IOT}

1. Identification technology, including a lot of technologies with different maturity, such as sensors, RFID, two-dimensional code, etc. Apperceive and identification technology is the foundation of IOT, which is responsible for capturing the events and data of physical world, realizing the perception and recognition of the outside world information.

2. Network and communication technology, including access, network, communication and frequency control. Network is the infrastructure of information transmission and service support, and it can realize high reliability and high security transfer of sensory information and control signal through ubiquitous interconnection function.

3. Computing and service technology, including information computing and service computing. Computing and processing of massive apperceive information is the core of IOT, services and applications is the final value reflects of IOT.

4. Management technology, including network management and security, measurement analysis, etc. With the scale expand of IOT, the diversification of network business, the improvement of service quality requirements and the increase of factors affecting normal operation of network, management and support technology has become the key to ensure IOT "being able to be run - being able to be managed - being able to be controlled".

\subsection{Development direction of IOT}

In order to develop IOT technology, we should pay attention to cultivate the inter-disciplinary talents prospectively. However, as IOT involves in many links such as apperceive, information transmission, signal processing and application, different talents are demanded by designing, building, operating, managing and maintaining posts of IOT application system, so IOT industry need a large number of specialized personnel of different directions.

For university of application technology, because of many restrictions such as education policy, school orientation, financial support, level of scientific research, experimental equipment, level of teachers, and quality of students, the intelligent sensor design and manufacture, network management and securiy are its weakness, so it should give up these two directions actively.

University of application technology have some superiority on configuration and realization of NFC, because it generally sets up network engineering major and have reserve of teachers, equipment and experience. In accordance with the communication protocol of NFC, students are able to learn the configuration technology of related equipments. On the other hand, the students of key university maybe disdain to do this work, and that will provide the good opportunity for the students of university of application technology.

Software development and integration service of IOT can also be considered, because this work requires practitioners to have certain software design ability, and university of application technology generally have computer science and technology major and software engineering major, in the aspect of software design, the gap between it and key university is not too large, university of application 
technology can do teaching work well as long as it strengthens teaching of courses related to software development and integration service of IOT.

Based on above analysis, university of application technology should focus on the direction of configuration and implementation of NFC and the direction of network software development and service integration, construct talent training scheme and supporting curriculum system suitable to IOT engineering major.

\section{ABILITY DEVELOPING SCHEME OF IOT}

\subsection{Training target of IOT engineering major}

To train the advanced application technology talents with comprehensive development of moral, wisdom and body, mastering related natural science basic knowledge of mathematics and physics, mastering basic knowledge, basic method, basic theory and basic skill of sensor, RFID, communication, network and automatic control, with the stronger professional practice ability, being qualified for application system planning, analyzing, design, management and maintenance work of IOT.

\subsection{Quality requirements of IOT major students}

1. To have good political quality, noble moral character, physical and mental health, good human quality and professional ethic, a strong sense of social responsibility.

2. To master natural science knowledge such as mathematics and physics required in professional work, and to be familiar with the basic knowledge of economics, management, system engineering and control theory, etc.

3. To master basic knowledge and theory of IOT engineering major systematically, to understand the concept of two-way integration of the physical world and the digital world, and to possess a clear concept of system architecture of IOT.

4. To acquire specialized knowledge of sensor, RFID, communication, information processing, IOT industry applications, and to have core professional competence related to IOT, such as environmental apperceive, signal capturing, signal transmission, signal and information processing, IOT application system construction and maintenance.

5. To learn the thought and research method of IOT, to have better ability to analyze problem and solve problem, and to be able to solve practical problems in the professional work using owned knowledge, method and technique.

6. To know current status and development trend of IOT industry, and to have innovation ability of technology, product, application, management and marketing.

7. To have self-learning ability and professional adapting ability, and to have basic ability and quality to pursue the adjacent professional work.

8. To have certain ability to work independently, interpersonal communication skills, cooperation ability and management ability.

9. To have certain ability of English listening, speaking, reading, writing and translating, and to be able to understand and learn IOT developing trend, new knowledge and new technology by English.

\subsection{Construction thought of IOT engineering major}

We should consider the following aspects to design talent training scheme of IOT engineering major for university of application technology.

(1) To position the university of application technology accurately, to put education quality in the first place, and to take technology as seriously as knowledge. 2014 is another "more difficult year of employment" and the Chinese graduates have reached 7.27 million. However, many enterprises can not recruit suitable talent, and the first-line technical talent shortage is close to $50 \%$. On one hand, students cannot find jobs; on the other hand, enterprises cannot find suitable employees. This contradiction is due to the disconnect between high education and social demand. Many universities do not know the industry demand of talent, they run school with closure mode, set training goals themselves, evaluate themselves, "enjoy themselves", resulting in higher education can not meet the demand of key interests stakeholders of students, industry and national. Facing this situation, it is very necessary that the central government proposed the education reforms strategy "To speed up the system construction of modern vocational education, to deepen the integration of production and education, to deepen the cooperation of school and enterprise, to cultivate high-quality workers and skilled talents.

We must accurately position the university of application technology, own a clear direction and firm determination, take training the blue collar "technical master" as our goal and responsibility, need not mind "academic" label, do not care of "study" reclame. As long as we think highly three key benefits stakeholders of students, industry and national, we must gain social approval steadily. When we set curriculum, we must pay attention to the applied technology courses, as to theoretical courses, we can select the basic theory which is enough for application, need not excessively pursuit systematic and completeness of theory.

(2) To establish the wide discipline foundation, broaden graduates employment. All the time since, a lot of people think that they will be engaged in the 
professional work as they learn in the university. However, the reality is not so.

In the investigation report on employment and work ability of the 2007 session graduates of some Shanghai universities, there is an indicator of "the rate of work related to major". As to the statistical value of the indicator, Fudan University is $61 \%$, Shanghai Jiaotong University is 66\%, Shanghai International Studies University is 62\%, Shanghai University of Finance and Economics is 55\%, Tongji University is $72 \%$, Donghua University is $68 \%$, East China Normal University is 67\%, East China University of Science and Technology is $73 \%$, Shanghai University is $59 \%$. The average of nine universities is only $64.8 \%$.

The indicator of key university graduates in developed areas -- Shanghai is such low, so it must be lower in other regions or other universities. Along with the global economic recession and the employment pressure resulted from domestic university enrollment, the rate of work related to major of college graduates will be lower gradually. The survey data shows that, the students who truly are engaged in the work related to their major are less than $40 \%$ in the national scope, most of the students can only be engaged in work similar to their discipline. This situation can be called the "work related to discipline". Compared with the work related to major, work related to discipline is worse. However, in present situation of employment pressure, it would be desired for someone to have a work related to discipline. In order to meet the low-key demand for most students to have a work related to discipline, we should try to expand the scope of basic courses when we set curriculum.

(3) To pay attention to basic courses. There is a common saying that every skyscraper is built from the ground. When we set curriculum, we must strictly follow the principle of gradual and orderly progress, set enough professional foundation courses in accordance with the convergence between the precursor and the successor courses to lay a solid foundation for cultivation of students' professional ability. Neither is it allowed to appear loopholes or disconnect, nor is it allowed to appear upside down of order among the professional foundation courses.

(4) To cultivate students' work ability of IOT engineering major. Although the rate of work related to major of collage graduates continued to decline in recent years, the graduates of IOT are relatively easier to have a work related to their major owing to the fact that IOT engineering major is a new major and IOT engineering talents are in short supply. Therefore we should consider the collage graduates' work related to major as far as possible when we set curriculum, that is, we should provide necessary professional courses to train student's professional work ability. On the other hand, as IOT engineering major is a multi-disciplinary and comprehensive major, a lot of knowledge, skills and technologies are needed, it is very difficult for the students to complete full professional courses in the limited time in school. Therefore, we may consider setting two or three professional directions based on three layers of IOT--apperceive, network transmission and application. After completing discipline and major basic courses, each student selects a professional direction and studies hard on this direction to get the direct technical support for future work. In this way, students can be competent related work by simple training when they start to work.

(5) To retain further education possibility of students. According to investigation result, about $30 \%$ students in university of application technology hope to continue studying for master's degree. In order to truly teach students in accordance with their aptitude, we should consider the learning need of these students. We should research the postgraduate entrance examination problem of the discipline to which IOT engineering major belong and the similar disciplines, such as universities recruiting graduates of these disciplines, the examination subjects and reference materials, etc. Under the premise that there is little effect to other students of IOT engineering major, set up some basic disciplinary courses and major basic courses appropriately in accordance with postgraduate entrance examination subjects.

\section{CURRICULUM SYSTEM OF IOT}

In the undergraduate talent training scheme, there are some courses be set up in accordance with the provision of Education Ministry of China, we have no right to change. For example, Basic Principle of Marxism, Mao Zedong Thought and the Theoretical System of Socialism with Chinese Characteristics, Ideological and Moral Cultivation and Legal Basis, Outline of Modern Chinese History, Situation and Policy, College Sports, National Defense Education and Military Training, etc. The credit, period and opening semester of these courses must be strictly in accordance with the provision of Education Ministry, so we don't discuss these courses.

The curriculum system of IOT engineering major for university of application technology is described as following.

1. Basic courses of discipline: college English, higher mathematics, linear algebra, probability theory and mathematical statistics, college physics, basic circuit, electronic technology, principle of communication, computer application foundation, modern literature retrieval, management science.

2. Basic courses of major: Introduction to IOT, C language program design, data structure, principle and application of database, computer 
network foundation, professional English of IOT.

3. Main courses of major: advanced sensor technology, recognition technology of IOT, short distance wireless communication technology, design and implementation of the project of IOT.

4. Professional courses: wireless sensor network, programming technology of IOT, principle and application of MCU, positioning technology of IOT, embedded computing system, intelligent technology of IOT, modern logistics management, management of IOT, and security of IOT.

\section{CONCLUSION}

IOT engineering major began to set up in universities in the situation that related technologies and knowledge is not fully mature. The curriculum system and teaching method of every university is not perfect at present. We are still at the stage of practice and exploration. For this new major, every university has its own constructing thought, some universities rely on the second discipline of electronic information, and some universities rely on the second discipline of computer, while other universities rely on the second discipline of automation. By comparison of the talent training scheme of universities' IOT engineering major, we found that the talent training scheme of each university had the shadow of the second discipline which it relying on, meanwhile, it revealed the trace of related majors. Different universities' talent training schemes differed quite obviously. Just for one university, there was obvious difference between different versions of the talent training scheme of IOT engineering major, the new version of the talent training scheme gradually fade the shadow of the second discipline which it relying on, blanked the trace of the related majors, preliminary show the characteristics of talent training scheme of IOT engineering major. By comparison of different versions of the talent training scheme of many universities' IOT engineering major, we found that through many scholars' unremitting exploration in recent years, the talent training scheme of every university's IOT engineering major showed convergence sign which was the performance that IOT engineering major gradually got mature.

According to the time distribution of setting up IOT engineering major, it could be seen that the schools setting up IOT engineering major three years ago were mainly key universities, however, the schools setting up IOT engineering major in this three years were mainly the second level universities and a few of the third level universities. In the light of the trend of setting IOT engineering major, there would be more and more the second level universities and the third level universities to set up IOT engineering major, nevertheless, the existing talent training schemes and curriculum system of IOT engineering major of key universities are not completely suitable for these universities. Aiming at the position of university of application technology, and the characteristics of IOT engineering major of university of application technology, this paper developed the professional ability shaping scheme of IOT engineering major, and established the curriculum system of IOT engineering major. The research result has certain reference value for university of application technology to develop the talent training scheme and establish the curriculum system of IOT engineering major.

\section{REFERENCES}

[1] Guidelines of the State Council on promoting the healthy and orderly development of IOT. [EB/OL]. http://www.gov.cn/zwgk/2013-02/17/content_2333141.htm

[2] Analysis on the current situation of Chinese IOT industry(2011).

[EB/OL].

http://www.cctime.com/html/2012-2-28/20122281355330 028_2.htm

[3] Twelfth Five Year Plan of IOT. [EB/OL]. http://kjs.miit.gov.cn/n11293472/n11295040/n11478867/1 4344522.html

[4] Sun, Q. Liu, J. Li, S. Fan, C. \& Sun, J. 2010. IOT: the review of concept, architecture and key technology. Journal of Beijing University of Posts and Telecommunications 10(3): 1-9.

[5] Xu, X. Lu, Y. \& Yang, G. 2012. On the talent cultivation strategy of IOT major. Journal of Beijing University of Posts and Telecommunications 12(1): 119-124.

[6] Lu, J. 2014. Transformation of the university of application technology: based on education quality, think highly of theory and technology simultaneously. [EB/OL].

http://www.cssn.cn/gx/gx_gxxx/201408/t20140812_12876 51.shtml

[7] Liu, C. Qiu, S. \& Chen, M. 2012. An investigation report on the employment situation of graduates and non professional match. China University of Political Science and Law university "student innovation fund project" research paper. [EB/OL]. http://ge.cupl.edu.cn/cn/detail.php?id=707

[8] The analysis report on research and development trend ofChinese IOT industry (2013-2018). [EB/OL]. http://www.20087.com/DiaoYan/2013-05/WuLianWangSh iChangYanJiuBaoGao.html 